Abstract 368 Table 1

\begin{tabular}{|c|c|c|c|c|}
\hline & Case 1 & Case 2 & Case 3 & Case 4 \\
\hline $\begin{array}{l}\text { Age at diagnosis of morphea } \\
\text { (years) }\end{array}$ & 11 & 11 & 8 & 11 \\
\hline $\begin{array}{l}\text { Age at diagnosis of } \\
\text { thrombocytopenia (years) }\end{array}$ & 9 & 11 & 8 & 11 \\
\hline Classification of morphea & En coup de sabre & En coup de sabre & $\begin{array}{l}\text { En coup de sabre } \\
\text { (figure 1) }\end{array}$ & $\begin{array}{l}\text { En coup de } \\
\text { sabre }\end{array}$ \\
\hline $\begin{array}{l}\text { Haemoglobin }(\mathrm{gm} / \mathrm{L}) \text { (Normal } \\
\text { range 110-130) }\end{array}$ & 128 & 117 & 122 & 127 \\
\hline $\begin{array}{l}\text { White blood cell counts } \\
\left(\times 10^{\circ} \text { cell/ } / 2\right) \text { (Normal range } 40 \text {. } \\
110)\end{array}$ & 108 & 91 & 80 & 70 \\
\hline $\begin{array}{l}\text { Lowest platelet counts }\left(\times 10^{\circ} / \mathrm{L}\right) \\
\text { (Normal range } 150-400)\end{array}$ & 8 & 44 & 82 & 120 \\
\hline ANA (antinuclear antibody) & $\begin{array}{l}\text { Positive (2+ } \\
\text { speckled) }\end{array}$ & $\begin{array}{l}\text { Positive (3+ } \\
\text { homotenous) }\end{array}$ & Negative & Negative \\
\hline Anti double stranded DNA & Negative & Negative & Not done & Not done \\
\hline $\begin{array}{l}\text { Antibodies to extractable nuclear } \\
\text { antigens }\end{array}$ & Negative & Nezative & Not done & Not done \\
\hline Antiphospholipid antibodies & Positive & Negative & Negative & Negative \\
\hline Treatment for morphea & $\begin{array}{l}\text { Topical calcipotriol } \\
\text { ointment and } \\
\text { Injection anti D }\end{array}$ & Oral methotrexate & $\begin{array}{l}\text { Subcutaneous } \\
\text { methotrexate }\end{array}$ & $\begin{array}{l}\text { Sobcutaneous } \\
\text { methotrexate }\end{array}$ \\
\hline $\begin{array}{l}\text { Time to recovery of } \\
\text { thrombocytopenia }\end{array}$ & 1 month & 1 year & Sotll persisting & 4 months \\
\hline Follow up (months) & 78 & 54 & 10 & 8 \\
\hline
\end{tabular}

\section{A CASE OF HEMOPHATOCYTIC SYNDROME DEVELOPED IN A KOREAN FEMALE PATIENT WITH DERMATOMYOSITIS}

${ }^{1} \mathrm{JM}$ Kim*, ${ }^{2} Y \mathrm{G}$ Jeong, ${ }^{3} \mathrm{CH}$ Lee, ${ }^{4} \mathrm{HR}$ Jung. ${ }^{1}$ Keimyung University Dongsan Medical Centre, Division of Rheumatology- Department of Internal Medicine, Daegu, Republic of Korea; ${ }^{2}$ Changwon Fatima Hospital, Division of Rheumatology-Department of Internal Medicine, Changwon, Republic of Korea; ${ }^{3}$ School of Medicine- Wonkwang University, Division of Rheumatology- Department of Internal Medicine, Iksan, Republic of Korea; ${ }^{4}$ Keimyung University School of Medicine- Dongsan Medical Centre, Department of Pathology, Daegu, Republic of Korea

10.1136/lupus-2017-000215.369
Background and aims Dermatomyositis (DM) is characterised by chronic inflammation of striated muscle and characteristic cutaneous manifestations. Hemophagocytic syndrome (HPS) is a rare life-threatening condition caused by uncontrolled activation of histiocytes resulting in prominent hemophagocytosis. Particularly, occurrence of HPS in the patients with DM is extremely rare.

Methods We report the first case of HPS in a patient with DM successfully treated in Korea.

Results A 56-year-old female visited our hospital, complaining of general weakness with whole body skin rash for 2 months. She had symmetric proximal muscle weakness and characteristic skin lesions including heliotrope rash, gottron's papules 


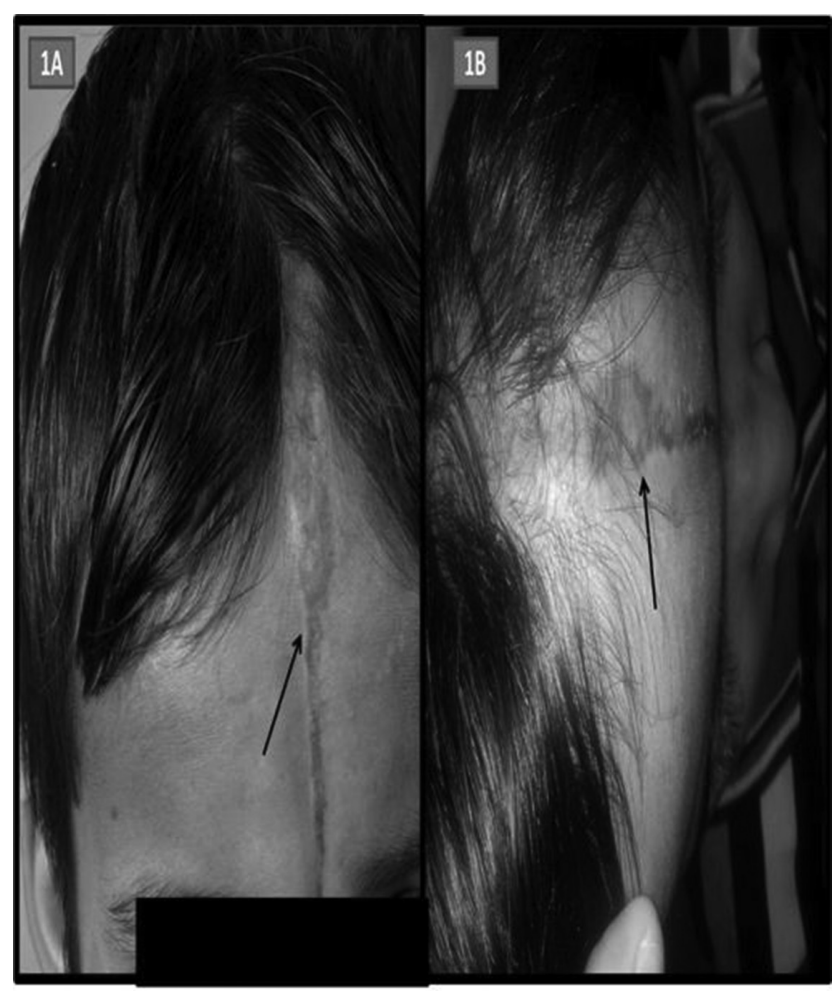

Abstract 368 Figure 1

and $\mathrm{V}$ sign. She also had swallowing difficulty proven by abnormal videofluoroscopic swallowing test. Laboratory findings showed anaemia, thrombocytopenia, elevated muscle enzymes, hyperferritinemia and hypertriglyceridemia. The autoimmune profile revealed positive antinuclear antibody (1:160, homogenous pattern) and negative anti-Jo-1 antibody. In addition to electromyography and skeletal muscle biopsy, bone marrow biopsy was performed to find the cause of microangiopathic hemolytic anaemia and thrombocytopenia. Numerous CD68-positive macrophages engulfing erythrocytes and platelets were revealed in bone marrow study. She was finally diagnosed as DM with secondary HPS. After steroid pulse therapy for 3 days, we continued high dose steroid therapy for 1 month. Thereafter, we gradually tapered the steroid and started methotrexate. After 1 year of treatment, she was completely recovered from muscle weakness, swallowing difficulty, skin lesions and cytopenia.

Conclusions With this unique case, we would like to assert that HPS should be considered when cytopenia is observed in the patients with DM and that early aggressive therapy is needed.

\section{THE CLINICAL CHARACTERISTICS OF SARCOID ARTHROPATHY BASED ON A PROSPECTIVE COHORT STUDY}

${ }^{1} \mathrm{~S}$ Kobak*, ${ }^{2} \mathrm{~F}$ Sever, ${ }^{3} \mathrm{O}$ Usluer, ${ }^{4} \mathrm{~T}$ Goksel, ${ }^{5} \mathrm{M}$ Orman. ${ }^{1}$ Istinye University Faculty of Medicine -LIV Hospital, Rheumatology, Istanbul, Turkey; ${ }^{2}$ Medicalpark Hospital, Chest Diseases, Izmir, Turkey; ${ }^{3}$ Suat Seren Chest Diseases Hospital, Chest Surgery, Izmir, Turkey; ${ }^{4}$ Ege University Faculty of Medicine, Chest Diseases, Izmir, Turkey; ${ }^{5}$ Ege University Faculty of Medicine, Statistics, Izmir, Turkey

10.1136/lupus-2017-000215.370
Background and aims Sarcoidosis is known as a Th1-mediated disease which can mimic many primary rheumatologic diseases or sometimes co-exist with them. Clinical characteristics of sarcoid arthropathy are not well described and the studies reported in the literature so far are mostly based on the data from referrals. The aim of this study was to evaluate the incidence and clinical characteristics of sarcoid arthropathy.

Methods All our patients were prospective evaluated in our single Rheumatology outpatient centre from 2011 to 2015. 114 patients with sarcoidosis were included in the study.

Results The mean patient age was 48.1 years and the mean disease duration was 40.5 months.Sarcoid arthritis was observed in 71 (62.3\%), and arthralgia in 106 (92.9\%) patients. Out of the 71 patients with arthritis, $61(85.9 \%)$ had involvement of ankle, 7 (9.8\%) knee, 2 (2.8\%) wrist, MCP and PIP joints, and one (1.4\%) had shoulder periarthritis. Oligoarthritis (two to four joints) was the most common pattern followed by monoarthritis and polyarthritis. When the correlation between clinical findings was considered, erythema nodosum and arthritis and female gender were found to be correlated $(p=0.03, p=0.001$, respectively). Again in patients with arthritis, even higher levels of CRP/ESR as well as ANA and RF positivity were observed $(p=0.03, p=0.01, p=0.01$ and $p=0.02$, respectively). Eleven patients had another rheumatic pathology concurrent with sarcoidosis.

Conclusions Inflammatory arthritis occurs in a majority of patients with sarcoidosis. Acute arthritis with bilateral ankle involvement is the most common pattern of sarcoid arthropathy. Sarcoidosis can mimic many primary rheumatic diseases and/or may coexist with them.

\section{THE USE OF HAND PERFUSION SCINTIGRAPHY TO ASSESS RAYNAUD'S PHENOMENON ASSOCIATED WITH HAND-ARM VIBRATION SYNDROME}

${ }^{1}$ SH Lee ${ }^{*},{ }^{1} \mathrm{KA}$ Lee, ${ }^{1} \mathrm{HR}$ Kim, ${ }^{2} \mathrm{HW}$ Chung. ${ }^{1}$ Konkuk University Medical Centre, Rheumatology, Seoul, Republic of Korea; ${ }^{2}$ Konkuk University Medical Centre, Nuclear medicine, Seoul, Republic of Korea

\subsection{6/lupus-2017-000215.371}

Background and aims This study aimed to evaluate the hand perfusion scintigraphic features of hand-arm vibration syndrome (HAVS) and to compare these with the features of primary and secondary Raynaud's phenomenon (RP) associated with rheumatic diseases.

Methods Hand perfusion scintigraphy was performed in 57 patients with primary RP, 71 patients with HAVS-related RP, and 36 patients with rheumatic disease-related RP. Patients' clinical details were collected by a retrospective review of medical records. We calculated 6 ratios by using the timeactivity curve and static blood pool images, the chilled to ambient hand and wrist ratios of the first peak height, initial slope, and blood pool uptake. We analysed 3 morphologic characteristics: slow progress pattern, paradoxically increased uptake pattern in the time-activity curve, and the inhomogeneous radioactivity uptake in the blood pool image.

Results All of the 71 patients with HAVS-related RP were mine workers. The onset of RP after exposure to vibration was at $21.8 \pm 7.3$ years, with $26.3 \pm 7.0$ years of vibration exposure time. The chilled to ambient hand ratios of the first peak height and the initial slope were significantly lower in patients with HAVS-related occupational RP than in patients with primary RP. The presence of a paradoxically increased 